\title{
A EXPANSÃO DO CURSO DE FORMAÇÃO DE PROFESSORES NA MODALIDADE DA EAD E PRESENCIAL NO BRASIL (2000 - 2018)
}

\section{ARTIGO ORIGINAL}

MORAES, Henaldo Barros ${ }^{1}$

ARAÚJO, José Carlos Souza ${ }^{2}$

MORAES, Henaldo Barros. ARAÚJO, José Carlos Souza. A expansão do curso de formação de professores na modalidade da EAD e presencial no Brasil (2000 2018). Revista Científica Multidisciplinar Núcleo do Conhecimento. Ano 05, Ed. 12, Vol. 05, pp. 127-153. Dezembro de 2020. ISSN: 2448-0959, Link de acesso: https://www.nucleodoconhecimento.com.br/educacao/expansao-do-curso

\section{RESUMO}

Este artigo apresenta as principais características da EAD bem como alguns dos fatos marcantes desta modalidade desde os seus primórdios até os dias atuais no Brasil. $\mathrm{O}$ objetivo desta pesquisa foi apresentar a modalidade da EAD e algumas comparações com a presencial, de forma que possa compreender a evolução experimentada nos últimos anos. A metódica da pesquisa é qualitativa e quantitativa tendo como base a literatura disponível na internet, e conteúdos fornecidos pelo MEC/INEP. Através de resultados fornecidos pelas Sinopses Estatísticas da Educação Superior, verificou-se que a EAD apresenta um crescimento muito desproporcional entre as regiões do país,

\footnotetext{
1 Doutorando em Educação pela Universidade de Uberaba, com previsão de término em 04/2021. Mestrado em Engenharia de Telecom com ênfase em Redes de Computadores pela Universidade Federal de Uberlândia - MG. Pós-graduação, latu senso, em segurança da informação pela Universidade Federal de Uberlândia - MG. Graduado em Ciência da Computação pela Universidade Federal de Uberlândia - MG. ${ }^{2}$ Orientador. Doutorado em Educação. Mestrado em História Social. Graduação em Teologia. Graduação em História. Graduação em Filosofia.
} 
e que cursos de formação de professores, tal como Pedagogia, vem experimentando crescimento contínuo nos últimos anos, o que permite concluir que muito em breve, uma grande quantidade de futuros professores pode estar concluindo seus cursos na modalidade da EAD. Ademais foi apresentado que o número de matriculas na modalidade da EAD vem experimentando crescimento muito acentuado se comparado com a redução sentida na modalidade presencial.

Palavras-chave: Educação a Distância, expansão, interiorização.

\section{INTRODUÇÃO}

De acordo com Ministério da Educação e Cultura (MEC) é a partir de 2002 que, no Brasil, a EAD inicia um processo muito acentuado de expansão no número de matrículas (BRASIL, 2003). Somente no período de 2014 a 2018, o número de matrículas experimentou um crescimento de 53,2\%, passando de 1.341 .842 para 2.056.511 matrículas (BRASIL, 2018).

$\mathrm{Na}$ modalidade da EAD, os cursos são mediados pelas Tecnologias Digitais de Informação e Comunicação (TDIC), as quais têm como objetivo substituir ou tentar aproximar, a relação entre professores e alunos mesmo que estes estejam em ambientes fisicamente distantes. Deste modo, ao invés de todos os participantes se encontrarem dentro de uma mesma sala de aula, com dia e horário marcados, os estudos podem ser praticados em horários, dias e localidades diferentes, através de um ambiente virtual de aprendizagem (AVA).

O número de instituições públicas que oferecem cursos de formação de professores na $E A D$, e que disponibilizam polos nas mais diversas regiões do país, tem crescido significativamente nos últimos 20 anos. Deste modo tem ocorrido crescimento no número de matrículas nos cursos de formação de professores, por meio da EAD, de forma acentuada em todo o país, pois passou de 99.109, em 2014, para 113.767 no ano de 2018, um crescimento de 14,78\% (BRASIL, 2018; BRASIL, 2014). 
A EAD surgiu concomitantemente em várias localidades do Brasil, à medida que a infraestrutura de telefonia móvel e fixa foi sendo implantada nas mais diferentes regiões. Outro impulso relacionado à interiorização da EAD foi a necessidade de democratização de educação superior para populações mais carentes, principalmente para aqueles usuários localizados em regiões mais afastadas dos grandes centros urbanos, bem como para aquelas pessoas que não mantêm flexibilidade de tempo para frequentar um curso presencialmente.

Dubet (2015) cita que o processo de democratização da educação compreende reverter uma situação pela qual a busca pela educação superior estaria para uma minoria considerada excepcionalmente talentosa. Neste caso, a democratização permite 0 acesso de alunos que são provenientes de camadas sociais mais modestas. O mesmo autor argumenta ainda que a democratização da educação superior permitiu a pessoas que antes nem imaginavam cursar uma faculdade, ter a oportunidade de concluir um curso superior.

As seções a seguir visa apresentar os principais marcos a respeito da evolução e implantação da EAD no país, mostrando fatos desde a criação até valores atuais desta modalidade.

\section{REFERENCIAL TEÓRICO}

Esta seção apresenta os principais fatos que marcaram a evolução a respeito da modalidade da EAD no Brasil. Por ser uma modalidade relativamente nova no Brasil, visto que iniciou nas IES públicas no ano 2000, muitas características ainda estão em constantes mudanças e nesta seção algumas serão brevemente apresentadas.

\subsection{DEFINIÇÕES DA EDUCAÇÃO A DISTÂNCIA}

No cenário que se encontra atualmente a $E A D$, é importante enfatizar as várias definições que são utilizadas a respeito deste termo. Sabe-se que alguns conceitos, muito utilizados na literatura, são frequentemente empregados para referir-se a diferentes tipos de atividades na EAD e muitos apresentam semânticas contrapostas 
e significados contrários. Alguns autores têm apresentado questionamentos contrários a respeito da validade do termo, Educação a Distância, por considerarem a presença física do aluno em sala de aula um quesito essencial dentro de uma experiência de educação.

No entanto, existem tantos outros autores defendendo que não há nenhum problema com a utilização deste termo, visto que é "possível a Educação a Distância, muitas vezes inclusive de maneira mais intensa e proveitosa do que no caso da educação presencial" (MAIA e MATTAR, 2007). Nesse sentido, o que se verifica é que não existe uma definição padrão para a Educação a Distância, tanto é que nos últimos anos vários autores apresentaram definições diferentes. São apresentadas, a seguir, algumas definições utilizadas por vários autores a respeito da modalidade de Educação a Distância.

De acordo com Dohmem (1967, p.73), a modalidade iria aproveitar-se da evolução da tecnologia em seus processos educacionais:

A Educação a Distância é uma forma sistematicamente organizada de auto estudo onde o aluno instrui-se a partir do material de estudo que Ihe é apresentado, e o acompanhamento e a supervisão do sucesso do estudante são levados a cabo por um grupo de professores. Isto é possível através da aplicação de meios de comunicação, capazes de vencer longas distâncias (DOHMEN, 1967, p.73).

Observa-se que nesta definição, o autor já se preocupa com as tecnologias para a transmissão de conteúdo para os alunos e vencer as longas distâncias para prover educação.

Segundo a Lei Francesa, (BELONI, 2001, p. 25), "O Ensino a Distância é o ensino que não implica a presença física do professor indicado para ministrá-lo no lugar onde é recebido, ou no qual o professor está presente apenas em certas ocasiões ou para determinadas tarefas". A mesma autora comenta que a EAD era vista como uma formação continuada, ou educação ao longo da vida, que fazia parte de um sistema bastante amplo de transmissão do conhecimento. 
Enquanto isso, Moore (1973, p.663), afirma que as ações do professor são totalmente independentes das ações realizadas pelos alunos. Observe-se sua afirmação:

Ensino a Distância pode ser definido como a família de métodos instrucionais onde as ações dos professores são executadas à parte das ações dos alunos, incluindo aquelas situações continuadas que podem ser feitas na presença dos estudantes. Porém, a comunicação entre o professor e o aluno deve ser facilitada por meios impressos, eletrônicos, mecânicos e outros (MOORE, 1973, p.663).

Nota-se a preocupação do autor em apresentar a comunicação como um meio fundamental dentro do processo de ensino. Para Holmberg (1977, p. 46), a modalidade da EAD é definida da seguinte forma:

O termo Educação a Distância esconde-se sobre várias formas de estudo, nos vários níveis que não estão sobre a contínua e imediata supervisão de tutores presentes com seus alunos nas salas de leitura ou no mesmo local. A Educação a Distância beneficia-se do planejamento, direção e instrução da organização do ensino (HOLMBERG, 1977, p.46).

Nesta definição o autor se preocupa em expor as formas de organização existente na estrutura de um curso de EAD, bem como o trabalho exercido por tutores.

Para Moore (1990, p.13), a Educação a Distância se apresenta da seguinte maneira:

A Educação a Distância é uma relação de diálogo, estrutura e autonomia que requer meios técnicos para mediatizar esta comunicação. Educação a Distância é um subconjunto de todos os programas educacionais caracterizados por: grande estrutura, baixo diálogo e grande distância transacional. Ela inclui também a aprendizagem (MOORE, 1990, p.13).

Segundo o autor, para que um curso na modalidade EAD cumpra a meta de oferecer um aprendizado efetivo, ele deve ir um pouco mais além. Para Perriault (1996, apud BELONI, 2001, p. 25), a modalidade da EAD apresenta denominações diferentes:

A Educação a Distância é um termo genérico que inclui o elenco de estratégias de ensino e aprendizagem referidas como "educação por correspondência", ou "estudo por correspondência" em nível pós-escolar de educação, no Reino Unido; como "estudo em casa", no nível pósescolar, e "estudo independente", em nível superior, nos Estados Unidos; como "estudos externos", na Austrália; e como "ensino a distância" ou "ensino a uma distância", pela Open University. Na França 
é referido como "tele ensino" ou ensino a distância; e como "estudo a distância" e "ensino a distância", na Alemanha; "educação a distância", em espanhol, e "tele-educação", em português (PERRIAULT 1996, apud BELONI, 2001, p. 25).

O autor tenta mostrar as várias denominações que a EAD recebe pelo mundo. Neste sentido pode-se verificar que na década de 1990 as denominações para o termo EAD eram diferentes entre os países. De outra forma, Chaves (1999, p. 37) propõe a seguinte definição para a Educação a Distância:

A EAD no sentido fundamental da expressão é o ensino que ocorre quando o ensinante e o aprendente estão separados no tempo e no espaço. No sentido que a expressão assume hoje, enfatiza-se mais a distância no espaço e propõe-se que ela seja contornada através do uso de tecnologias de telecomunicação e de transmissão de dados, voz e imagem (incluindo dinâmicas, isto é, televisão ou vídeo). Não é preciso ressaltar que todas essas tecnologias, hoje, convergem para 0 computador (CHAVES, 1999, p.37).

Nesta definição é exposto o quanto as TDIC já eram fundamentais dentro do processo de ensino e aprendizagem da EAD e como os computadores estavam se tornando a principal ferramenta tecnológica dentro deste processo.

Enquanto isso, Moran (2002, p.1) cita que "a Educação a Distância é um processo de ensino-aprendizagem, mediado pelas tecnologias, onde professores e alunos estão separados espacial e/ou temporalmente". Neste caso o autor considera o termo Educação a Distância mais apropriado do que Ensino a Distância, devido ao fato da EAD ser um processo com foco centrado na aprendizagem do aluno. Moore e Kearley (2007, p. 2), analisam a EAD da seguinte forma:

A EAD é o aprendizado planejado que ocorre normalmente num local afastado da IES, por isso exige que sejam utilizadas técnicas especiais de criação de curso e de instrução, e a comunicação ocorre por meio de várias tecnologias e disposições organizacionais e administrativas especiais (MOORE e KEARLEY, 2007, p.2).

Nota-se que, para os autores citados anteriormente, os processos de ensino e aprendizagem devem atuar conjuntamente e o mecanismo de aprendizagem deve 
acontecer de forma planejada. Para Peters (2009, p. 69), a EAD é analisada da seguinte forma:

A EAD não é apenas uma aprendizagem convencional com a ajuda de uma mídia técnica em particular. É uma abordagem totalmente diferente, com estudantes, objetivos, métodos, mídias e estratégias variadas e, acima de tudo, objetivos diferentes na política educacional. A Educação a Distância é sui generis (PETERS, 2009, p.69).

Verifica-se que para o autor, a EAD precisa se afastar do modelo de ensino tradicional para ser bem sucedida, visto que para ele no ensino convencional os mecanismos de ensino-aprendizagem não estão baseados nas formas típicas de ouvir e falar. Por fim, Brasil (2018b) coloca a seguinte definição sobre a EAD:

A Educação a Distância é a modalidade educacional na qual os alunos e os professores estão separados, física ou temporalmente e, por isso, faz-se necessária a utilização de meios e tecnologias de informação e comunicação. Essa modalidade é regulada por uma legislação específica e pode ser implantada na educação básica (educação de jovens e adultos, educação profissional técnica de nível médio) e na educação superior (BRASIL, 2018b).

Neste caso verifica a preocupação em expor a separação existente entre mestres e alunos, as tecnologias utilizadas e níveis de educação que podem ser utilizados.

Os exemplos apresentados nas definições do termo Educação a Distância e Ensino a Distância, citados anteriormente, mostram o quanto é complexo a definição do tema e também a falta de unanimidade sobre o assunto, verifica-se que alguns parâmetros estão presentes em todas as definições, enquanto outros não são explicitados claramente por nenhum dos autores.

De acordo com Houaiss (2009), o termo ensino é um ato ou processo que possui o efeito de transferir conhecimento, informações úteis e indispensáveis à educação. Diferentemente, o mesmo autor cita que o termo educação é o ato ou processo de educar-se, que visa a aplicação de métodos próprios para assegurar a formação e o desenvolvimento físico, intelectual e moral de um ser humano. 
Destaca-se que dentre as definições, citadas anteriormente, é mostrado o quanto é complexo estabelecer uma explicação a respeito do assunto, pois não existe unanimidade. A definição apresentada por Brasil (2018) me parece ser a mais próxima daquelas que temos encontrado na literatura atual, pois reforça a utilização no uso das TIC, na aproximação entre aluno e professor, e cita a importância dos meios regulatórios no desenvolvimento da EAD.

\subsection{AS GERAÇÕES DA EDUCAÇÃO A DISTÂNCIA}

O crescimento da EAD pode ser dividido em seis gerações de acordo com os aspectos que são analisados. Neste caso as gerações citadas são as seguintes:

1a Geração - É conhecida entre os especialistas como a geração do estudo por correspondência. Nesta fase os alunos recebiam todo o material que utilizavam para a prática dos estudos pelos correios, e enviavam para os tutores as atividades resolvidas para que fossem avaliadas. Após o período de correção, os alunos recebiam, via serviço postal, um feedback das avaliações. Foi um modelo de alta flexibilidade de estudo, considerando o tempo, o lugar e a capacidade de estudo de cada pessoa, mas ao mesmo tempo não apresentava uma comunicação adequada entre aluno e professor.

De acordo com Moore e Kearsley (2007), a perspectiva de usar a tecnologia, para chegar até aqueles que não podiam se beneficiar dela, foi o que mais motivou alguns educadores a utilizar o ensino por correspondência, e que pode ser observada em alguns profissionais que atuam na educação a distância. O ensino por correspondência representou uma oportunidade de estudo para pessoas que eram excluídas do processo educacional convencional.

2a Geração - Houve uma pequena inovação, pois utilizou da mídia impressa e da radiodifusão, por isso é conhecida como modelo multimídia. Nessa geração verificase que os materiais já apresentavam uma melhoria considerável na qualidade dos conteúdos distribuídos. Nos EUA, as rádios universitárias foram utilizadas para transmitir os conteúdos da EAD, para oferecer cursos aos próprios alunos das 
instituições de ensino. Na Europa, a inserção das emissoras de rádio na divulgação de conteúdos da EAD, ocorreu de forma constante. No inicio, os áudios foram utilizados para auxiliar na educação de cegos e também em cursos de idiomas (MOORE; KEARSLEY, 2007).

$3^{\text {a }}$ Geração - Nessa geração houve mudanças mais consistentes se comparado às gerações anteriores. As mudanças foram resultadas de diversas experiências com novas formas de organização da tecnologia e de recursos humanos, que trouxeram novas formas de instrução e teorização da educação. Nessa geração, foram dois os projetos desenvolvidos, sendo um pela Universidade de Wisconsin - Madison (EUA) e o outro pela Universidade Aberta da Grã-Bretanha, os quais foram considerados um marco na consolidação da educação distância (MOORE; KEARSLEY, 2007). O primeiro foi o Projeto Mídia de Instrução Articulada (AIM), da Universidade de Wisconsin, EUA, que tinha como proposta agrupar várias tecnologias de comunicação da época para prover um ensino de alta qualidade e de baixo custo para alunos que não eram universitários.

O segundo projeto foi realizado pela Universidade Aberta da Grã-Bretanha (Open University) ou UA que, no início, teve um crescimento enorme com relação ao número de alunos. Esta instituição passou a utilizar a mais completa gama de tecnologias de comunicação existentes, com o objetivo de ensinar um currículo universitário completo para qualquer pessoa adulta que tivesse o desejo de receber educação.

4" Geração - Foi marcada pelo uso das teleconferências, e ocorreu de forma mais acentuada com o desenvolvimento dos sistemas de comunicação e com o surgimento das fibras óticas, o que permitiu a transmissão em larga escala de áudio e vídeo em tempo real, de forma full-duplex com alta qualidade.

5ª Geração - É a geração pela qual a EAD alcançou a maior expansão de toda a sua história. Para alguns autores é a geração da internet, pela qual as aulas e todas as interações são realizadas com a utilização da rede de computadores e demais dispositivos, trocando informações pela rede em tempo real. De acordo com Moore e Kearsley (2007), o uso de computadores conectados à rede mundial (internet) 
aumentou de forma significativa as oportunidades da prática de estudos da EAD. Atualmente, 2020, observa-se que o acesso a materiais para o estudo à distância se tornou simples, visto que, até mesmo através de um dispositivo de celular, é possível acessar estes conteúdos digitais estando em regiões longínquas. Nessa geração, o estudo à distância é potencializado pelas conferências por computador e pelas interconexões existentes que facilitam de forma significativa a distribuição de materiais entre os participantes.

Niskier (1999) considera que nenhuma das tecnologias utilizadas nas gerações anteriores, há pouco comentadas, deixou de ser utilizada com a chegada da internet. $\mathrm{Na}$ realidade, o que houve foi uma adaptação da utilização dessas tecnologias com a chegada da rede mundial de comunicação, de forma que surgiu uma agregação de valores por melhores resultados.

6a Geração - Segundo Luzzi (2007), esta geração chegou com a integração da Realidade Virtual (RV) na produção de materiais com som e imagem em 3D, o que permite que os alunos possam imergir num mundo virtual que emula, de forma bem próxima, a realidade vivida pelos discentes da EAD. A RV permite maior interação do aluno com o material produzido devido às movimentações inseridas no texto.

\subsection{HISTÓRIA DA EDUCAÇÃO A DISTÂNCIA NO BRASIL}

Baseado nos acontecimentos que ocorrem, a nível mundial, nos últimos anos, em relação ainda à modalidade de $E A D$, sabe-se que no Brasil sua evolução é basicamente marcada pelo surgimento e grande disseminação dos meios de comunicação. Em todos os setores, verifica-se uma disponibilidade enorme de tecnologia e na educação isso não é diferente, principalmente em se tratando de EAD.

Nos primórdios de seu surgimento, a EAD passou por várias etapas de desenvolvimento, entre elas pode-se destacar a fase da correspondência, do rádio, da televisão, até chegar à fase atual, na qual se pode verificar uma utilização conjugada dos meios de comunicação, imensamente beneficiados pelo surgimento da 
Internet. A história da EAD no Brasil é marcada por muitos avanços ao longo dos anos, mas também se pode verificar que houve retrocessos ao longo de sua existência.

Percebe-se também que houve períodos em que a EAD praticamente permaneceu estagnada, provocada principalmente pela falta de investimento do governo federal em criar políticas públicas que fossem de encontro às necessidades de crescimento da EAD. De acordo com Alves (2009), até o ano de 1970, registros mostram que o Brasil estava entre os principais países do mundo, com melhores referências em se tratando da EAD, pois existia uma quantidade enorme de institutos que investiam em EAD com cursos não formais. Infelizmente, após esta data, o país praticamente estagnou e não mais apresentou grandes evoluções ou projetos que permitissem destaque em relação a outros países.

Somente no final do último milênio, o Brasil voltou a apresentar projetos consideráveis para modalidade da EAD, mas devido ao grande período de inércia, o caminho a percorrer ainda é longo e cheio de desafios a serem superados. As primeiras ações ou experiências em EAD, realizadas no Brasil, provavelmente não foram documentadas, mas os principais registros conhecidos são datados do início do século XX.

Segundo Maia e Mattar (2007), a EAD no Brasil foi iniciada com uma publicação que foi registrada nos classificados de anúncio no Jornal do Brasil em 1904, quando oferecia um curso de profissionalização por correspondência para datilógrafo. Esse curso era ministrado por professoras particulares, e não por instituições de ensino, tratando-se então de iniciativas isoladas. No ano de 1923, surgiu um grupo liderado por Henrique Morize e Edgard Roquette-Pinto que criou a emissora de Rádio Sociedade do Rio de Janeiro. Tal emissora passou a oferecer cursos, para a sociedade carioca, de Português, francês, Silvicultura, Literatura Francesa, Esperanto, Radiotelegrafia e Telefonia.

No inicio, a rádio funcionou numa escola superior que era mantida pelo poder público, mas posteriormente foram colocadas algumas exigências que eram difíceis de serem cumpridas, pois a emissora não tinha fins lucrativos. Os programas criados foram 
muito bem recebidos pela sociedade, mas despertaram certa preocupação aos governantes, pois, segundo eles, os programas podiam conter conteúdos inadequados aos interesses da época (ALVES, 2009).

Com o objetivo de criar um projeto para a Secretaria Municipal de Educação do Rio de Janeiro, Edgard Roquette-Pinto, instalou em 1934 a Rádio Escola para auxiliar os alunos na prática dos estudos. Nesse projeto de ensino, os alunos tinham acesso prévio aos folhetos e aos esquemas de aula e o contato também era realizado por correspondência. Posteriormente, em 1939, surgiu em São Paulo o Instituto Monitor, uma escola pioneira em oferecer cursos profissionalizantes por correspondência. Esta escola foi fundada por um imigrante húngaro, Nicolás Goldberger, que tinha conhecimento em eletrônica e resolveu instalar seu negócio em São Paulo. Esta escola funciona até os dias atuais oferecendo cursos Técnicos, Profissionalizantes, Supletivo, Normas, Gestão Corporativa bem como cursos superiores (ALVES, 2009). Nestes exemplos verifica a presença da primeira, segunda e terceira geração nestes processos de divulgação de conteúdo, pois houve utilização acentuada de recursos impressos e do rádio.

Em 1941, com o intuito de oferecer cursos na modalidade EAD, surge o segundo instituto no Brasil, o Instituto Universal Brasileiro (IUB). Este foi fundado por um exsócio do Instituto Monitor, e constituiu-se no maior e principal difusor de cursos profissionalizante à distância no país no decorrer do século XX. Este instituto exerceu suas atividades, até o ano de 1999, utilizando as correspondências como forma de contato, mas a partir do ano 2000 passou a oferecer cursos através da Internet. Neste período fica marcado como a mudança para quarta geração, pois utilização da internet passou a ser considera na disponibilização de conteúdo.

No ano de 1947, com o patrocínio do Serviço Nacional de Aprendizagem Comercial (SENAC), Serviço Social do Comércio (SESC) e de emissoras associadas, surge a Universidade do $\mathrm{Ar}$ com o objetivo de oferecer cursos comerciais radiofônicos. O curso era todo ele apostilado, e as dúvidas relacionadas a conteúdo eram resolvidas com auxílio de monitores. Em 1950 chegou a atingir 318 localidades de operação, mas 
teve que encerrar suas atividades em 1961, mas o SENAC continua com suas atividades em EAD até os dias atuais (ALVES, 2009; RUBIO, 2011).

Em 1959, surgiu o Movimento de Educação de Base (MEB). Este movimento teve sua origem através da criação das escolas radiofônicas pela Igreja Católica através da Diocese de Natal, RN. Este fato representa um marco na EAD não formal no Brasil, visto que envolvia a Conferência Nacional dos Bispos do Brasil (CNBB) e o Governo Federal. O MEB utilizou de um sistema educativo, com a utilização do rádio, para democratizar o acesso à educação através de cursos de letramento de jovens e adultos.

Em 1967, utilizando-se do ensino por correspondência, o Instituto Brasileiro de Administração Municipal inicia suas atividades na área de administração pública. Neste mesmo ano, a Fundação Padre Landell de Moura criou seu núcleo de EAD, com transmissão de conteúdos através de correspondência e do rádio (RUBIO, 2011). Nestes exemplos verificamos a presença da segunda geração devido a utilização do rádio e dos materiais impressos.

Em 1970, utilizando-se de um convênio entre o Ministério da Educação, a Fundação Padre Landell de Moura e a Fundação Padre Anchieta, foi criado o Projeto Minerva, que propunha novas alterações no processo educativo com a utilização do rádio e da televisão. Este projeto propunha a implantação de uma cadeia de rádio e televisão educativas para criar um processo de educação de adultos em massa. Um dos principais objetivos do mesmo era a preparação de alunos para exames supletivos de capacitação, sendo implementado como uma solução em curto prazo aos problemas de desenvolvimento do país (RUBIO, 2011). A presença da terceira geração é sentida nesta fase devido ao uso intenso de transmissão de recursos pela TV.

Sendo a pioneira na utilização da EAD, no ensino superior no Brasil, em 1979 a Universidade de Brasília (UNB) criou cursos veiculados por jornais e revistas. O setor de criação destes cursos foi transformado em Centro de Educação Aberta, Continuada, e a Distância (CEAD). Vale ressaltar que, nesse mesmo ano, foi lançado o Brasil EAD. 
No ano de 1981, com o objetivo de fornecer Ensino Fundamental e Médio à Distância, é fundado o Centro Internacional de Estudos Regulares (CIER) do colégio AngloAmericano. Com a criação do CIER, as crianças, filhas de famílias brasileiras que mudassem para o exterior, podiam continuar estudando pelo sistema nacional.

Em 1995, foi criado o Centro Nacional de Educação a Distância da MultiRio (RJ), responsável por ministrar cursos através de programas televisivos, utilizando-se material impresso. Ainda nesse mesmo ano, foi criado pela Federação das Indústrias de São Paulo (FIESP) e pela Fundação Roberto Marinho o Telecurso de $1^{\circ}$ e $2^{\circ}$ Grau. Neste, os materiais são compostos por livros e vídeos que permitiam aos alunos realizarem as atividades em várias tele salas existentes (RUBIO, 2011). Neste caso nota a presença da terceira geração devido ao uso dos recursos de TV na transmissão de conteúdo.

Outro fato relevante ocorrido no ano de 1995 foi a criação da Associação Brasileira de Educação a Distância (ABED), uma sociedade científica voltada para o desenvolvimento da EAD.

Com tantos fatos marcantes na década de 1990, o grande marco foi a criação da Secretaria de Educação a Distância (SEED) em 1996 pelo MEC, dentro da política de democratização da educação brasileira. Nesse mesmo ano, a EAD surge oficialmente no Brasil, tendo como bases legais para a mesma a Lei de Diretrizes e Bases da Educação (LDB), no 9.394, de 20 de Dezembro de 1996, que foi regulamentada em 20 de Dezembro 2005 pelo Decreto № 5.622 (BRASIL, 2005).

No ano de 2000, foi formado um consorcio de várias instituições públicas no Brasil, que se sentiam comprometidas com a democratização do ensino no país; esse consorcio, denominado de UniRede, oferecia cursos de graduação, pós-graduação e extensão na EAD.

De acordo com a Capes (2018) no ano de 2005, é criada a Universidade Aberta do Brasil (UAB), uma parceria entre o MEC, os estados e os municípios, cujo objetivo era oferecer formação inicial a professores em atividade na educação básica da rede 
pública. Nesta etapa a transmissão de conteúdo ocorre de forma muito acentuada através da internet, e a produção de materiais com recursos de RV, prevalecendo, desde modo, a quinta e sexta geração.

\subsection{OS MARCOS LEGAIS DA EAD NO BRASIL}

As bases legais da EAD foram estabelecidas pela LDB, Lei o 9.394 de 20 de dezembro de 1996. Foi a partir da publicação desta Lei que a modalidade da EAD integrou de forma definitiva o sistema de ensino brasileiro. No artigo 80 da LDB, que foi regulamentado pelo Decreto ํㅡ 2.494/1998, ficou definido o que é a EAD bem como as suas disposições, o que possibilitou a criação de novos cursos dentro da modalidade. De acordo com Pereira (2016), este Decreto não contemplou todos os cursos oferecidos, pois não foram inseridos mestrado, doutorado e muito menos os cursos que conferem certificado de conclusão para ensino fundamental, ensino médio, graduação e educação profissional.

De acordo com Moran (2005), no ano de 2001 veio a público a Portaria do MEC no 2.253, pela qual ficou definido que os cursos de graduação, na modalidade presencial, poderiam oferecer até $20 \%$ de suas disciplinas em EAD; no mesmo ano, o Conselho Nacional de Educação (CNE) elaborou normas para o funcionamento de cursos de graduação, lato sensu, na mesma modalidade. Posteriormente, no ano de 2004, a Portaria do MEC no 4.059 revogou a Portaria № 2.253 de 2001. Pela nova portaria foram expressas normas para o oferecimento de disciplinas na EAD, prevendo a utilização das TDIC, os encontros presenciais e as atividades de tutoria presencial e à distância.

Alterando a Portaria ํㅜ 1.428, veio a público pelo MEC, a Portaria ํo 2.117 que permite aos cursos de graduação na modalidade presencial disponibilizar até $40 \%$ de sua carga horaria na modalidade de EAD, com exceção dos cursos de medicina. A mesma portaria condiciona a introdução de conteúdos na modalidade de EAD a cumprimento de regras estabelecidas pelas Diretrizes Curriculares Nacionais (DCN) de cada um dos cursos. 
$\mathrm{Na}$ LDB/1996, a criação de cursos experimentais é facultativo as IES, e isso permite que as instituições possam inserir novas experiências, tais como a oferta de disciplinas na modalidade semipresencial nos cursos de graduação, deste modo a Portaria ํㅡ 4.059/2004 traz referências a respeito da criação dessas disciplinas.

Foi a partir da publicação da Portaria ํo 4.059/2004 que cria a possibilidade da oferta de disciplinas semipresenciais por parte das IES, no entanto ficou definido que a avaliação continua sendo presencial.

Nesta mesma Portaria, ํo 4.059, ficou definido que os cursos de graduação stricto sensu, mestrado e doutorado, ficam sujeitos às exigências de autorização e reconhecimento que estão previstas em lei, e a aprovação por parte do Conselho Nacional de Educação e da Capes. Contrariamente, os cursos lato sensu são independentes de autorização por parte destes órgãos.

Ainda no ano de 2004, a Portaria de № 4.361 revogou a Portaria № 301/1998, a qual incluiu normatizações para o credenciamento de cursos na modalidade de EAD.

No ano de 2005, foi promulgado o Decreto ํㅜ 5.622, regulamentando os artigos 80 e 81 da Lei 9.394/96, definindo que a EAD se caracteriza como uma modalidade educacional que utiliza as TDIC para mediar os processos de ensino e aprendizagem. Esta mesma Lei preconiza que a modalidade de EAD necessita obrigatoriamente de momentos presenciais para a realização de avaliações, estágios obrigatórios, defesas de TCC e atividades realizadas em laboratórios (ANDRADE, 2008).

O Decreto 6.303/2007 altera a redação do Decreto no 5.622/2005, estabelecendo a exigência de polos presenciais para EAD, e definindo estes como uma unidade operacional no país para o desenvolvimento das atividades pedagógicas a distância. $O$ decreto cita que as atividades avaliativas, deverão ser realizadas na sede da instituição ou no polo de apoio presencial.

Foi com a promulgação da Lei 9.394/96 que ficou estabelecido que a partir do ano de 2006 todos os profissionais que viessem a ser contratados, para ministrarem aulas no ensino fundamental e médio, deveriam possuir pelo menos o terceiro grau completo. 
Esta exigência causou uma procura excessiva em busca de qualificação por parte de professores que não apresentavam habilitação, permitindo uma demanda excessiva por cursos na modalidade de EAD. E foi através do Decreto 5.800/2006 que foi instituída a UAB, com propósito de interiorizar a educação no país (ANDRADE, 2008).

No dia 6 de dezembro de 2019, veio a público, pelo MEC, a Portaria ํo 2.117 que permite aos cursos de graduação na modalidade presencial disponibilizar até $40 \%$ de sua carga horária na modalidade de EAD, com exceção dos cursos de medicina. $A$ mesma portaria condiciona a introdução de conteúdos na modalidade de EAD, em vista de cumprimento de regras estabelecidas pelas DCN de cada um dos cursos (SEMESP, 2020).

\subsection{POLÍTICAS PÚBLICAS NA FORMAÇÃO DE PROFESSORES NA MODALIDADE À DISTÂNCIA}

Foi a partir do acordo de cooperação técnica № 4/1993, firmado entre o MEC e a Universidade de Brasília (UNB), que o governo federal deu os primeiros passos para a criação de uma política direcionada para cursos de formação de professores na modalidade de EAD no Brasil.

Nesse acordo, ficou definido que tanto o MEC quanto a UNB seriam os responsáveis pela coordenação do Consórcio Interuniversitário de Educação Continuada e à Distância (BRASILEAD). Ficou determinado que as IES que participassem deste consórcio seriam responsáveis pela formação de professores para a Educação Básica devido à carência existente destes profissionais. Ressalta-se ainda que em 1994, o MEC criou o Sistema Nacional de EAD (SINEAD), com o objetivo de erradicar o analfabetismo e universalizar o ensino fundamental (PEREIRA, 2016).

De acordo com o Brasil (2018b), as políticas públicas implantadas no Brasil, para cursos de formação de professores na modalidade de EAD, foram inseridas no país a partir de movimentações realizadas por parte do governo federal e estadual. 
Neste sentido no ano de 1991 foi criado, para atuar na formação de professores na modalidade de EAD, o programa Salto Para o Futuro, com uma proposta de formação continuada voltada para o ensino Fundamental, Médio e algumas séries da Educação Infantil. Este programa foi implantado pelo MEC, tendo como parceiros a Secretaria de Educação Básica (SENEB) e a Fundação Roquete Pinto. É composto, em sua estrutura, por orientadores educacionais que são os responsáveis por coordenar os trabalhos em aproximadamente 600 polos, distribuídos por todo o território brasileiro (BRASIL, 2019).

No ano de 1997 foi criado Programa Nacional de Informática na Educação (Proinfo). Este programa tem como objetivo suprir as escolas de infraestrutura de computação, pois permite a instalação de dispositivos de informática, computadores, nas escolas públicas do Ensino Básico. (RUBIO, 2011).

Foi nos estados de Mato Grosso e Mato Grosso do Sul que no ano de 1999 iniciou, em caráter experimental, o programa de formação de professores em exercício, que teve a denominação de Proformação. Este curso é de nível médio, em EAD, com habilitação em magistério para professores que não possuem habilitação para exercerem a carreira de professor (BERBAT, 2015).

No ano de 1999, um consórcio reunindo mais de setenta IES, públicas, sendo elas federais, estaduais e municipais, criaram a Universidade Virtual Pública do Brasil ou UniRede. Esse consórcio foi criado com o objetivo de democratizar o acesso ao ensino superior público e de qualidade, através de cursos de graduação e pós-graduação para a formação de professores (UNIREDE, 2020).

Com o objetivo de disponibilizar um ambiente colaborativo de aprendizagem a distância o MEC criou, em 2001, a plataforma e-Proinfo. É uma plataforma que permite o desenvolvimento de diversos tipos de ações, tais como a implementação de cursos a distância, complementação de cursos presenciais, projetos de pesquisa e ao processo de ensino-aprendizagem, tudo disponibilizado gratuitamente para as instituições públicas. 
No ano de 2002 o governo de Minas Gerais criou o projeto Veredas para atuar na formação de professores no ensino superior, utilizando a modalidade da EAD. Foi instituído pela Secretaria Estadual de Educação com o objetivo de atuar na formação de professores leigos para atuar no ensino fundamental na rede pública estadual e municipal (RODRIGUES, 2009).

Foi lançado no ano de 2005 o pró-licenciatura, projeto que tinha como objetivo atuar na formação de professores na modalidade da EAD. Tal incentivo foi lançado em parceria com as IES públicas para implantar cursos de Licenciatura na EAD.

Também no ano de 2005 foi instituído pelo governo federal o programa Próletramento, cujo objetivo é fornecer formação continuada de professores na melhoria da qualidade da leitura, escrita e matemática nas séries iniciais do ensino fundamental. Os cursos oferecidos funcionam de forma semipresencial e utiliza material impresso e em vídeo, contando com atividade presencial e na EAD (ALFERES; MAINARDES, 2012).

Com o objetivo de superar a falta de professores, formados, para atuar na educação básica, o MEC constituiu, em caráter emergencial no ano de 2005, o programa Prolnfantil. Um programa, de nível médio, que opera na modalidade semipresencial para capacitar professores que estão no exercício efetivo de suas atividades na rede pública municipal e estadual, e nas instituições privadas sem fins lucrativos (BARBOSA, 2012).

O Programa de Consolidação das Licenciaturas (Prodocência) é um programa que iniciou na Secretaria de Educação Superior do MEC no ano de 2006. Tem como objetivo aumentar a qualidade dos cursos de formação para o magistério da educação básica, através do apoio a projetos que estimulem a inovação, e que possuem novas formas de gestão escolar e proponham renovação da estrutura acadêmica e curricular dos cursos (MONTANDON, 2013).

Com o objetivo de promover a capacitação de professores da rede pública da educação básica, o governo federal lançou em 2009 o Plano Nacional de Formação 
de Professores para Educação Básica (Parfor). É um programa que é conduzido pela Capes, em parceria com governos estaduais e municipais, e tem como objetivo capacitar, e consequentemente valorizar profissionais para atender a demanda existente da educação brasileira, além disso, garantir as exigências de qualidade em todos os níveis da educação básica exigida pela LDB (SILVA, 2018).

\section{DESENVOLVIMENTO DO TRABALHO}

Esta seção apresenta o desenvolvimento do trabalho, mostrando os principais resultados a respeito da evolução da EAD no país, com base nos dados divulgados pelo MEC/INEP.

\subsection{EDUCAÇÃO SUPERIOR A DISTÂNCIA NO BRASIL}

A oferta de cursos na modalidade EAD teve uma expansão mais centrada nas IES localizadas nas regiões sul e sudeste. A partir do ano de 2002, com a entrada das IES privadas na modalidade da EAD, observa-se um crescimento muito acentuado em todas as regiões do Brasil. O Gráfico 1 apresenta o crescimento do número de matrículas, nos cursos de EAD, no período de 2002 a 2018 por região. 
Gráfico 1 - Evolução do Número de Matrícula em EAD por Região

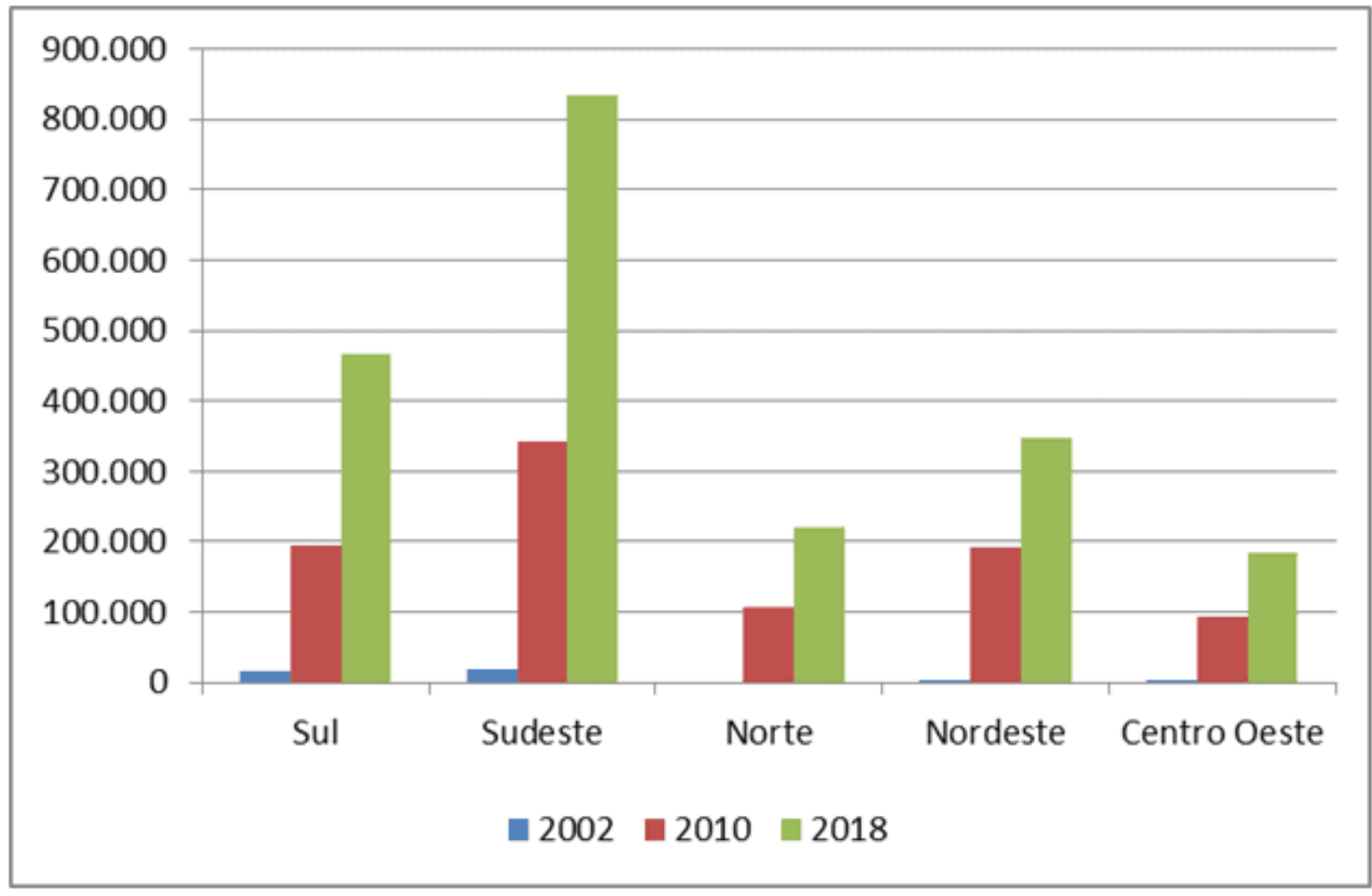

Fonte: Elaborado pelo autor com base em Brasil (2018)

Verifica-se no Gráfico 1, que desde 2002 o número de matrícula vem aumentando de forma muito significativa em todas as regiões do Brasil, com destaques para as regiões sul e sudeste, que dentro do período mencionado mais do que dobraram o número de matrículas nos cursos na EAD.

No Brasil a educação superior, na EAD, deu seus primeiros passos na década de 1990, mas começou a se consolidar definitivamente a partir do ano de 2000, com o provimento de cursos pelas Instituições Públicas de Ensino Superior (IPES). A expansão da internet, pelo interior do país, teve um papel fundamental nesse cenário, pois foi a partir deste marco que instituições como a Universidade Federal de Santa Catarina (UFSC) e a Universidade Federal do Mato Grosso (UFMT) iniciaram seus primeiros projetos com oferta de cursos superiores á distância.

As bases legais com relação à Educação a Distância foram estabelecidas pela LDB, Lei n.․ 9.394, de 20 de Dezembro de 1996, na qual o artigo 80 inseriu a EAD no Brasil 
em todos os níveis, evidenciando a importância desta modalidade no contexto da educação nacional e por sua inserção nos Planos Nacionais de Educação (BRASIL, 1996).

Dados do Brasil (2018), publicados no segundo semestre de 2019, mostram que mais de $28,47 \%$ das matrículas efetuadas no ensino superior foram realizadas em cursos na modalidade a distância, na qual foram alcançados a quantidade de 2.450.264 matrículas em 2019. Vale ressaltar que no ano de 2000 , o percentual de matrícula da modalidade em EAD era de apenas $0,19 \%$. O Gráfico 2 apresenta a evolução do número de matrículas no ensino presencial e na EAD, nas IES públicas e privadas nos últimos anos.

Gráfico 2 - Evolução do Número de Matrícula do Ensino Presencial e da EAD

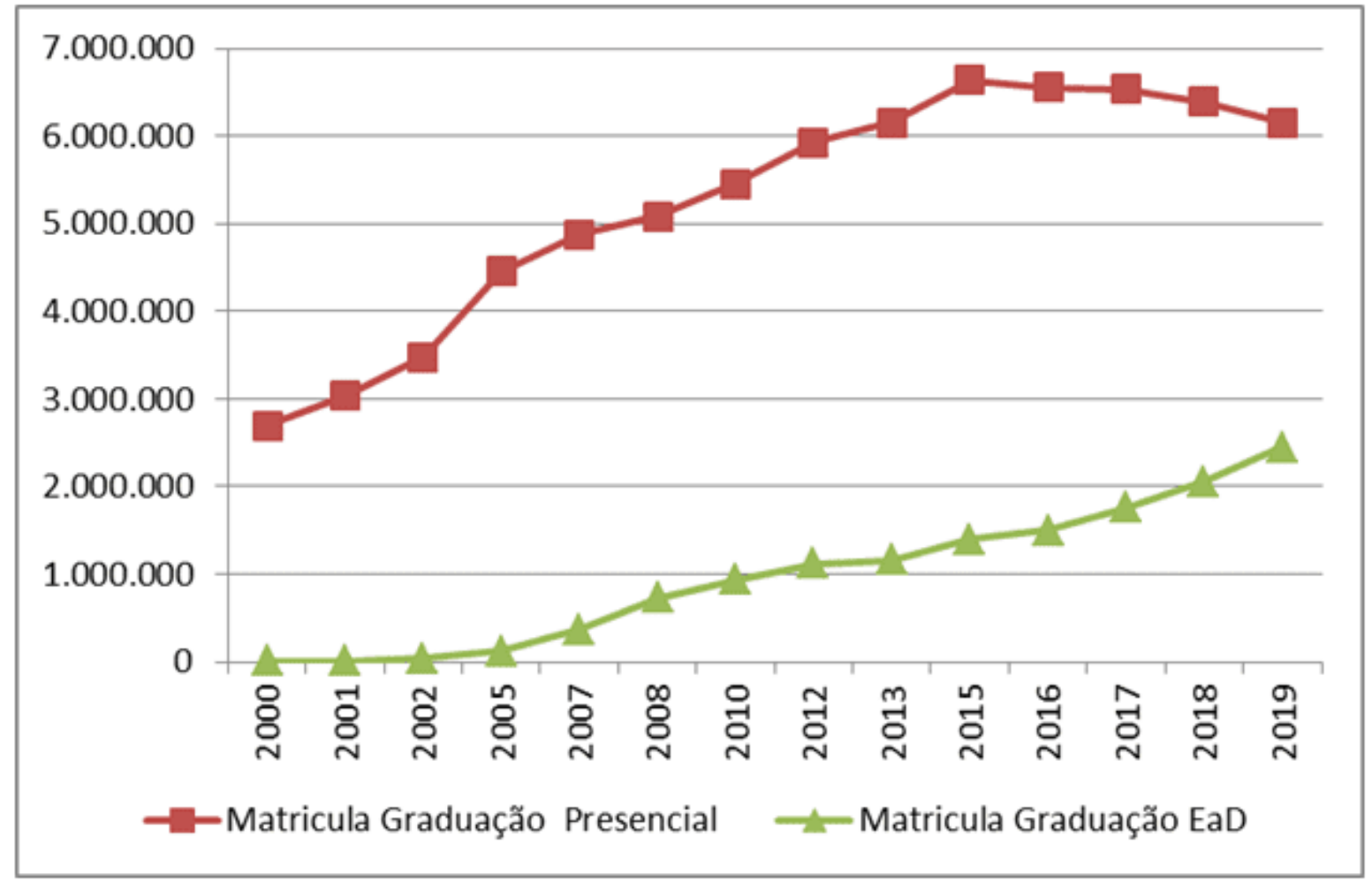

Fonte: Elaborado pelo autor com base em Brasil (2019) 
Constata-se no Gráfico 2 que enquanto no ensino presencial, no período de 2000 a 2018 , houve um crescimento de aproximadamente $137,3 \%$ no número de matrículas, na modalidade da EAD, no mesmo período, o crescimento foi de $122.165 \%$

A importância da EAD para a educação superior pode ser reforçada pelo número de alunos matriculados nesta modalidade. Um exemplo é o curso de Licenciatura em Pedagogia que apresenta um número de matrícula muito acentuado. De acordo com Brasil (2019), o número de matrícula neste curso, na modalidade da EAD, já ultrapassou, de forma muito significativa, o número de alunos na modalidade presencial. O Gráfico 3 mostra a evolução do número de matrícula para o curso de Pedagogia, no Brasil, a partir do ano de 2009 numa comparação entre a modalidade da EAD e a Presencial.

Gráfico 3 - Número de Matrícula em Pedagogia na Modalidade Presencial e EAD

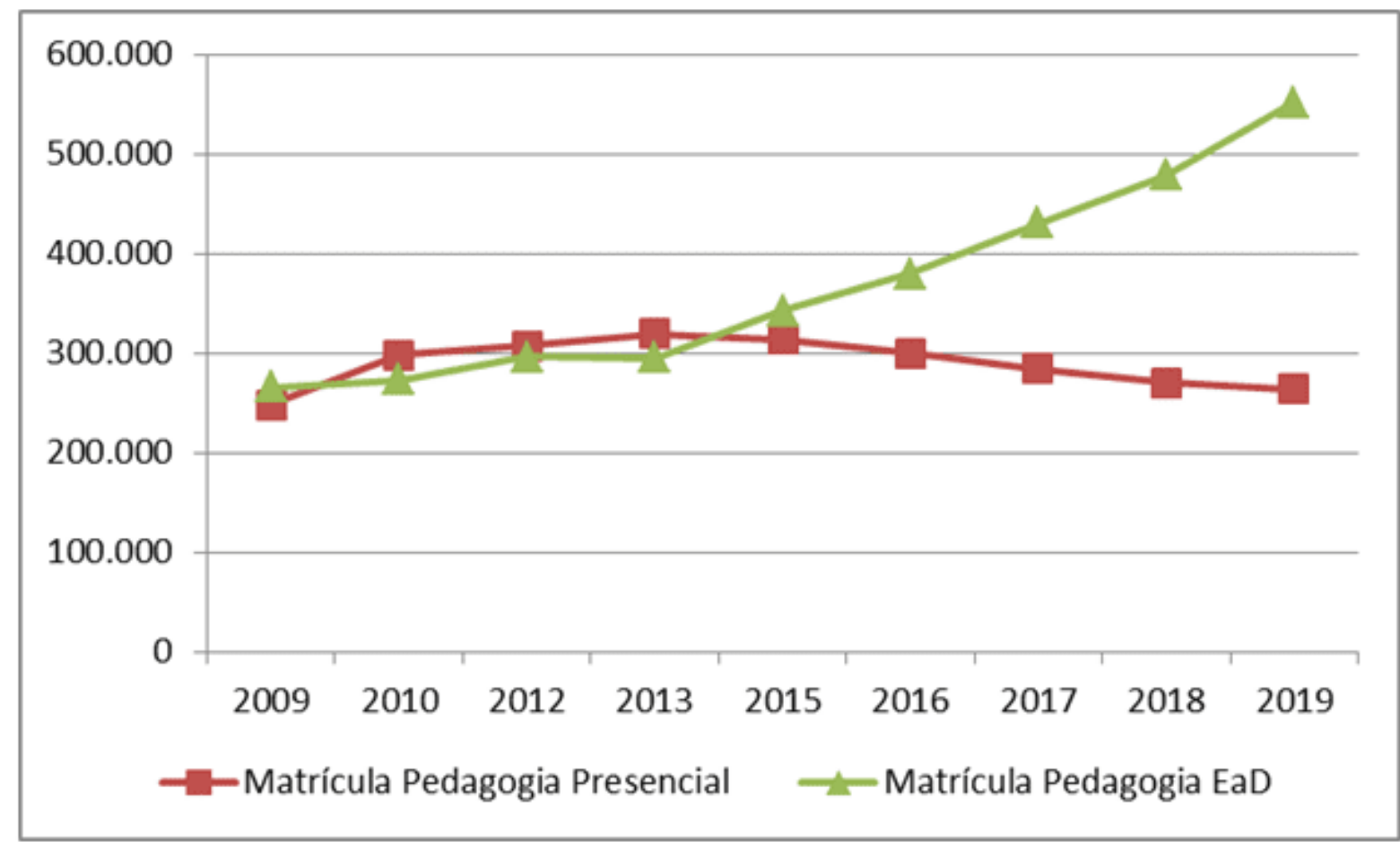

Fonte: Elaborado pelo autor com base em Brasil (2019)

Pelos dados apresentados no Gráfico 3, verifica-se que enquanto no curso de Pedagogia na modalidade presencial no período apresentado, de 2009 a 2019, houve 
um crescimento de $6,61 \%$ no número de matrículas, para o mesmo curso e no mesmo período de tempo, na modalidade da EAD, houve um crescimento de $108 \%$ no número de matrículas realizadas. $O$ mesmo gráfico mostra que, aproximadamente, a partir do ano de 2014 o número de matrículas em Pedagogia, na modalidade presencial, iniciou um processo contínuo de diminuição e, contrariamente à modalidade da EAD, a quantidade de matrículas tem aumentado significativamente a partir do ano de 2013.

\subsection{O CONTEXTO DOS CURSOS DE LICENCIATURA E CARACTERÍSTICAS DOS LICENCIADOS}

No período de 2001 a 2017 é observado um crescimento bastante acentuado do número de matrícula nos cursos de formação de professores na EAD. Especificamente para o curso de Pedagogia, verifica-se que este curso obteve um crescimento de aproximadamente $64,3 \%$ neste período. O Gráfico 4, a seguir, apresenta a variação experimentada no número de cursos de Pedagogia, Educação Básica e Matérias Específicas dentro do período de 2001 a 2017, tanto nas instituições públicas quanto nas privadas na EAD.

Gráfico 4 - Número de Cursos de Formação de Professores nas IES Públicas e Privadas.

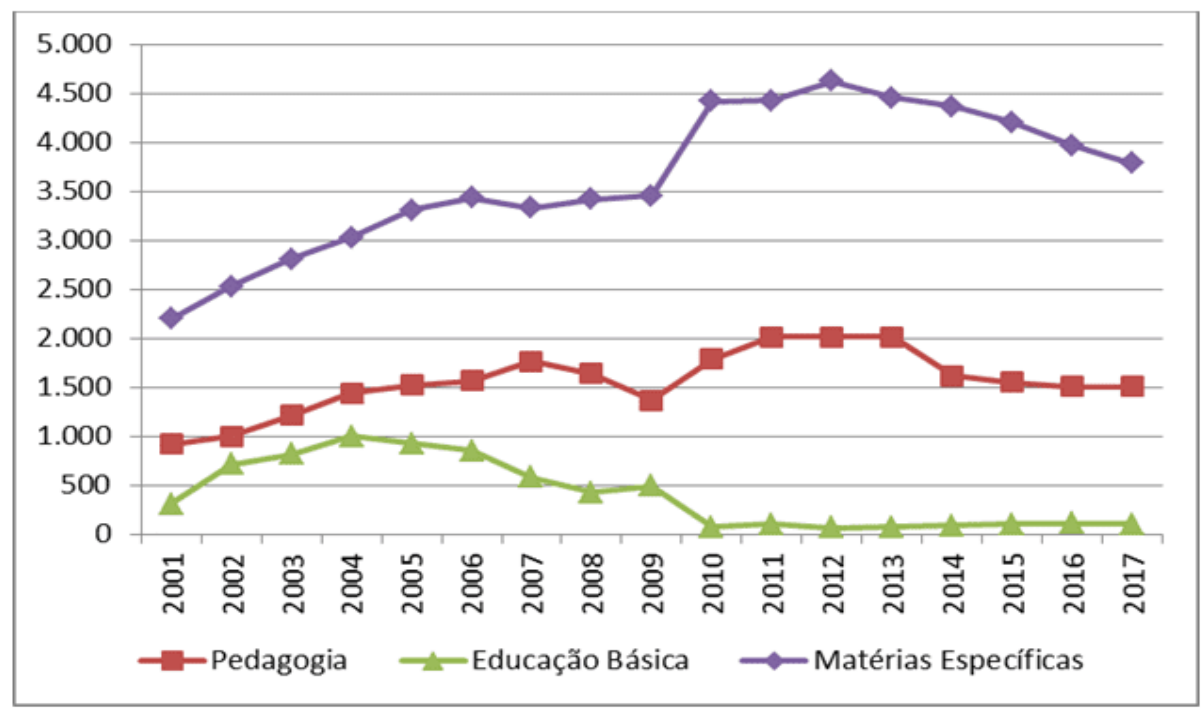

Fonte: Elaborado pelo autor com base em Brasil (2017) 
No Gráfico 4 é possível verificar que dentro do período analisado os cursos de formação de professores de Matérias Específicas sofreram um aumento bastante significativo e próximo de $72,4 \%$, já os cursos de formação de professores para Educação Básica tiveram uma redução, na quantidade de curso, de $34,31 \%$ no período analisado. Por fim, verifica-se que para o curso de Pedagogia a taxa de crescimento foi de $64,4 \%$ dentro do mesmo período. Analisando o gráfico, verifica-se que nos últimos anos os cursos de formação de professores vêm experimentando uma diminuição bastante acentuada no número de ofertas.

\section{CONSIDERAÇÕES FINAIS}

Neste artigo foi apresentada algumas das principais características que marcaram a EAD nos últimos anos no Brasil. Informações relacionadas aos primórdios, bem como aquelas que marcam a atualidade, da modalidade, foram citadas neste artigo.

Foi apontado que a EAD vem experimentando crescimento em todo o país, no entanto, existem regiões que possui expansão muito tímida em relação as outras, o que permite concluir que o processo de democratização da educação através da EAD possui um caminho longo para ser atingido. Atualmente a expansão e interiorização vêm ocorrendo de forma muito concentrada nas regiões sul e sudeste do país, enquanto em outras regiões esta movimentação ainda é muito pequena. Além disso, foi apresentado a evolução no número de matriculas entre as modalidades presenciais e EAD, e verificou-se, que nesta, o crescimento vem se mostrando muito continuo e progressivo ao longo dos anos, enquanto na presencial vem ocorrendo uma queda bastante significativa nos últimos anos.

Através de dados divulgados pelo MEC/INEP verifica-se que o curso de pedagogia na modalidade presencial vem passando por um processo de redução no número de matrículas muito acentuado desde o ano de 2012, enquanto isso o mesmo curso na modalidade da EAD, vem experimentando crescimento de forma continua e progressiva desde o ano de 2009. Atualmente o que se nota é que mesmo com alguns curso de Licenciatura mantendo queda no número de matrícula, contrariamente, o curso de Pedagogia é o que possui o maior crescimento em número de matrículas 
dentre todos aqueles que são providos na modalidade da EAD, com mais de 478.000 matrículas realizadas.

Por fim conclui-se que os cursos de formação de professores na EAD, tanto nas IES pública quanto nas privadas, têm se mantido com número de matriculas em patamares aceitáveis, mas com destaque para o curso de Pedagogia oferecido na modalidade da EAD.

\section{REFERÊNCIAS}

ALFERES, Marcia Aparecida.; MAINARDES, Jefferson. Formação Continuada de Professores Alfabetizadores: uma avaliação do programa Pró-letramento, Revista Meta, vol. 4, o 10, p. 1-27, 2012.

ALVES, João Roberto Moreira. A História da EaD no Brasil. 2ํㅡㄴ Capítulo do livro: Educação a Distância o Estado da Arte. LITTO, F. M. e FORMIGA, M. Pearson, 2009, São Paulo.

BARBOSA, Ivone Garcia. O Prolnfantil e a Formação do Professor. Retratos da Escola, vol. 5, no 9, p. 175-177, 2012.

BELLONI, Maria Luiza. Educação à Distância. $2^{\mathrm{a}}$ edição. Campinas - SP, Autores Associados, 2001.

BRASIL. Censos Escolares da Educação Superior/ Sinopses Estatísticas da Educação Superior - 2003. Brasília, DF: Ministério da Educação/Instituto Nacional de Estudos e Pesquisas Educacionais Anísio Teixeira. Disponíveis em: <<http://inep.gov.br/sinopses-estatisticas-da-educacao-superior>>.

BRASIL. Decreto Lei no 5.622, de 19 de dezembro de 2005. Regulamenta o artigo 80 da Lei no 9.394, de 20 de dezembro de 1996, que estabelece as diretrizes e bases da educação nacional. Brasília, DF, 2005. Disponível em: <<http://portal.mec.gov.br/seed/arquivos/pdf/dec_5622.pdf >>. 
BRASIL. Censos Escolares da Educação Superior/ Sinopses Estatísticas da Educação Superior - 2014. Brasília, DF: Ministério da Educação/Instituto Nacional de Estudos e Pesquisas Educacionais Anísio Teixeira. Disponíveis em: <<http://inep.gov.br/sinopses-estatisticas-da-educacao-superior>>.

BRASIL. Decreto Lei no 5.622, de 19 de dezembro de 2005. Regulamenta o artigo 80 da Lei no 9.394, de 20 de dezembro de 1996, que estabelece as diretrizes e bases da educação nacional. Brasília, DF, 2005. Disponível em: <<http://portal.mec.gov.br/seed/arquivos/pdf/dec_5622.pdf >>.

BRASIL. Censos Escolares da Educação Superior/ Sinopses Estatísticas da Educação Superior - 2017. Brasília, DF: Ministério da Educação/Instituto Nacional de Estudos e Pesquisas Educacionais Anísio Teixeira. Disponíveis em: <<http://inep.gov.br/sinopses-estatisticas-da-educacao-superior>>.

BRASIL. Censos Escolares da Educação Superior/ Sinopses Estatísticas da Educação Superior - 2018. Brasília, DF: Ministério da Educação/Instituto Nacional de Estudos e Pesquisas Educacionais Anísio Teixeira. Disponíveis em: <<http://inep.gov.br/sinopses-estatisticas-da-educacao-superior>>.

BRASIL. Ministério da Educação e Cultura. Universidade Aberta do Brasil (UAB). 2018b, Disponível em:<< http://portal.mec.gov.br/busca-geral/248-programas-eacoes-1921564125/uab-universidade-aberta-do-brasil-382561829/12265universidade-aberta-do-brasil-uab>>.

BRASIL. Censos Escolares da Educação Superior/ Sinopses Estatísticas da Educação Superior - 2019. Brasília, DF: Ministério da Educação/Instituto Nacional de Estudos e Pesquisas Educacionais Anísio Teixeira. Disponíveis em: <<http://inep.gov.br/sinopses-estatisticas-da-educacao-superior>>.

BRASIL. Salto Para o Futuro. 2019, Disponível em: $\quad<$ http://portal.mec.gov.br/acessibilidade-sp-940674614/111-tv-mec-818951690/tvescola-1440558247/13258-salto-para-o-futuro-sp-1346571866 >>. 
BRASIL. Instituto Nacional de Estudos e Pesquisas Educacionais (INEP). Anuário da Educação Básica: 2018b - Brasília: INEP/MEC, 2019.

CAPES. 0 Que é a UAB. 2018, Disponível em: < http://www.capes.gov.br/acessoainformacao/informacoes-classificadas/93conteudo-estatico/7836-o-que-e-uab>>, 2018.

CHAVES, Eduardo. Conceitos Básicos: Educação a Distância. EdutecNet: Rede de Tecnologia na Educação, 1999. Disponível em: <<http://www.edutecnedet.com.br>> Acesso em: Nov. 2018

DOHMEN, Gunther. Das Fernstudium, Ein Neues Pädagogisches Forschungsund Arbeitsfeld. DIFF, Tübingen, 1967.

DUBET, François. Qual Democratização do Ensino Superior? Caderno $\mathrm{CrH}$, vol.28, ํo 74, p.255-266, 2015.

HOLMBERG, Borje. Distance Education: A survey and bibliography, 1977, ERIC. HOUAISS, Antônio.; VILLAR, Mauro Sales.; Franco, Francisco Manoel. Dicionário Houaiss da Língua Portuguesa. Rio de Janeiro, Ed. Objetiva, 2009.

LUZZI, Daniel. Angel. O Papel da Educação a Distância na Mudança de Paradigma Educativo: da visão dicotômica ao continuum educativo. Tese, USP, 2007.

MAIA, Carmem.; MATTAR, João. ABC da EaD: a Educação a Distância hoje. $1^{\text {a }}$ edição, Pearson, São Paulo, 2007.

MONTANDON, Maria Izabel. Políticas Públicas Para a Formação de Professores no Brasil: os programas Pibid e Prodocência, Revista da ABEM, vol. 20, no 28, 2013.

MOORE, G. Michael. Recent Contributions to The Theory of Distance Education. Open Learning, vol 5, № 3, p.10-15, 1990. 
MOORE, G. Michael. Toward a Theory of Independent Learning and Teaching. The Journal of Higher Education, 1973. ISSN 0022-1546.

MORAN, José Manoel. O Que é Educação a Distância, Jornal, 2002, São Paulo.

MORAN, José Manoel.; FILHO, Manoel Araújo. A Ampliação dos Vinte por Cento a Distância, XII Congresso Internacional de EAD da Associação Brasileira de Educação a Distância, 2005.

MOORE. G. Michael. KEARSLEY, Greg. Educação a Distância: uma visão integrada. Jornal, vol. 139, p.125-140, 2007, São Paulo.

NISKIER, Arnaldo. Educação a Distância: a tecnologia da esperança. Jornal, vol. 2001, 1999, São Paulo.

PEREIRA, Daniela Oliveira. A Educação a Distância nas Políticas Públicas de Formação Continuada de Professores, SIED: EnPED - Simpósio Internacional de Educação a Distância e Encontro de Pesquisadores em Educação a Distância, 2016.

PETERS, Otto. A Educação à Distância em Transição: tendências e desafios. São Leopoldo: Editora Unisinos, 2009.

RODRIGUES, Lavínia Rosa. Projeto Veredas: os sentidos da formação para as professoras de Caeté - MG, Dissertação de Mestrado, UERJ, 2009.

RUBIO, Claudete Paganucci. Uma Modalidade de Ensino na Educação: educação a distância. Tese. Universidade Estadual Paulista, 2011.

SEMESP - Sindicato das Entidades Mantenedoras de Estabelecimentos de Ensino Superior no Estado de São Paulo. 2020, Portaria MEC no 2.117 de 6 de dezembro de 2019. Disponível em; <<https://www.semesp.org.br/legislacao/portaria-mec-no-2-117de-6-de-dezembro-de-2019/>>. 
SILVA, Herodoto Ezequiel Fonseca.; SILVA, Marcio Oliveiros Alves. O Estudo Sobre a Formação do Professor de Língua Portuguesa no Parfor Letras, vol. 14, no 33, p.60-72, 2018.

ANDRADE, Cacilda Soares. Educação a Distância Online: uma proposta pedagógica para expansão do ensino de Ciências Contábeis, Tese, UFPE, 2008.

UNIREDE. Universidade Virtual Pública do Brasil, Histórico da UniRede, 2020, Disponível em: <<https://www.aunirede.org.br/portal/quem-somos/historico/>>

Enviado: Novembro, 2020.

Aprovado: Dezembro, 2020. 